on the basis of $\$ 2.50$ an ounce for the extract was $\$ 1.22$ for half an ounce, or 14 grams. The second, which chanced to be made at a cooler time, cost 55 cents for a half ounce, or $\$ 1.10$ for the ounce, while the third cost $\$ 1$ for half an ounce, or $\$ 2$ an ounce. Inasmuch as two grains of the extract was enough to color a gallon of solution, he did not regard the cost as of much consequence. It had about 300 times the power of the ordinary cudbear.

F. W. Nitardy, referring to the question put by Mr. Cook, asked if anyone had ever tried mixing the cudbear with sand before percolating it. He had used that method in the laboratory with fairly good results.

\title{
WHAT IS ADULTERATION?
}

THEODORE J. BRADLEY, BOSTON, MASS.

The title of this paper presents a query that admits of many answers. It is almost like asking "What is a gentleman?" or "What is an education?" questions on which there is a wide difference of opinion, though, fortunately, some definiteness of conception. The popular idea of adulteration is that it always consists of the addition of cheaper ingredients, often harmful, to foods, beverages, drugs, confectionery, and other commodities. Very likely this was the original form of adulteration and it is often practised, but it comes very far from comprising the whole meaning of the word.

The number of causes by which an article may depart from standard quality is large and a complete list of them is difficult to give. The matter is complicated by the fact that several causes may effect a single case and there is much overlapping among them. The following are most important, the examples given being selected from a large number of possible ones, and they are not all from pharmaceutical sources.

I. Admixture with a foreign substance. This is the traditional and direct form of adulteration as exemplified by the crude notion of using sand to adulterate sugar. The dilution of milk with water is a simple and common example of this form of adulteration. It has been carried to ingenious lengths, as in the manufacture of cheese from skimmed milk which contains oleomargarine added to replace the butter fat.

II. Abstraction of valuable constituents, as the selling of spices and drugs from which important constituents have been extracted; of skimmed milk as whole milk, and many other instances.

III. Sale of an imitation for the genuine article, as colored diluted acetic acid for cider vinegar, colored diluted alcohol for whiskey, butterine for butter, acidulated solution of epsom salts for citrate of magnesia, etc. Some of these artificial products had such an illegitimate birth as this, but have become well known and now have a market of their own.

IV. Substitution, or the sale of one article under the name of another. This closely resembles the preceding but differs enough from it to be considered separately. We must confess that pharmacists have frequently been sinners in this respect. Examples are found in the sale of carbolic acid for creosote, acid phosphate of lime and other chemicals for cream of tartar, various coal-tar products for each other, and so on. 
$V$. Variation from standard strength, as in the case of many pharmaceuticals like the diluted acids and various galenicals having a standard alkaloidal strength. It is important to remember that too great a strength is as objectionable as the other.

VI. Offering for sale of deteriorated or decomposed articles, as diluted hydrocyanic acid, spirit of nitrous ether and other drugs which have lost their strength, more or less completely, and decomposed meats and other food products, including ice cream containing the deadly ptomains.

VII. Flavoring, coloring, or otherwise treating an article of inferior quality to make it appear to be of superior quality and selling it as such. An example of this is found in the so-called "renovated" butter which is low grade butter melted, washed with soda and otherwise made over.

VIII. Addition of harmful preservatives or coloring agents, many of which are likely to be used in canned and bottled goods of all kinds, and in pastry.

IX. Variation from standard quality because of improper or incomplete methods of manufacture, as the omission of the necessary aging of whiskey, the incomplete extraction of drugs and other instances. This also includes the failure to standardize certain preparations after manufacture, if this is called for.

$X$. Shortage of weight or measure. The common custom of calling twentyfour ounces a quart in bottling wines, and using the liquid quart in place of the dry quart are examples of this. Short weight seidlitz powders are familiar to some pharmacists.

XI. Failure to properly label when there is any ingredient present whose nature or amount should be stated, as in preparations containing morphine and some other alkaloids and preparations containing alcohol. Imitations, substitutions, and failures to properly label are all referred to as "Misbranding."

This is a formidable list, and it is not easy to give a brief definition of adulteration, though one is needed. Perhaps the best short definition that can be given is about like this:

A substance is adulterated when it differs in any respect from the properties, strength or quality which have been defined by some competent authority.

In the case of drugs the principal authorities are the United States Pharmacopoeia, and the National Formulary, and the National Board of Food and Drug Inspectors.

The present widespread agitation against adulteration was begun about fifteen years ago, probably because of the so-called "embalmed" beef furnished to our soldiers during the Spanish war. There are great copy making possibilities in the subject that appeal to the sensational writer, so the newspapers and magazines have been flooded with articles on it. This is of advantage in awakening and educating the public on the matter, but no one should allow himself to be misled into believing that all foods, drugs, beverages and confectionery, nowadays, are subject to adulteration, harmful or otherwise. To those who are informed on the conditions existing twenty-five and more years ago, the present outcry is like setting a trap after the game has taken the bait. It is a comforting fact that, with the exception of milk and its products, comparatively few cases of the adulteration of staple foods are found at the present time. When Massachusetts, 
New York and other states began investigating and regulating adulteration, in the early eighties, conditions were indeed bad and a great deal of time could be spent in citing old instances of adulteration by the crudest of methods. This, however, is now a matter of history and it is enough to say that the persistent campaign begun then, and continued until the present, has greatly reduced the number and kind of offenses of this sort, but it has not entirely done away with them.

Like all callings, pharmacy has men of many kinds within its ranks, and among them there have been some who have been deliberate adulterators, but, after more than ten years' experience in a state laboratory having charge of the inspection and control of the quality of the drugs sold in the state, the writer is firmly convinced that the pharmacist is very seldom a deliberate adulterator of his wares. On. the other hand, because of carelessness or ignorance, he frequently sells or dispenses goods that are adulterated and it is difficult to make some pharmacists understand that they are responsible for this adulteration whether it is deliberate or not.

The enforcement of laws regulating adulteration should be carried out with great discretion by men well informed on the subject. A distinction between deliberate or harmful adulteration and gross carelessness or negligence on the one hand, and unintentional and inoffensive slight variation from standards, due to oversight, on the other, must be made. The sensationalist or over-zealous man in office, by a mechanical enforcement of laws and regulations, often does great injustice to men who are essentially innocent of any wrong. Fortunately such officers are not often upheld by the public and their careers are short, but some individuals may suffer greatly because of their misdirected zeal. The rational method of dealing with the subject is to prosecute and punish, ordinarily, only the persistent and deliberate and serious offenders. It is a fact that notification to the pharmacist of his offense is nearly always sufficient to stop a particular case of adulteration and it amounts to a persecution to severely punish a man who is anxious to do the right thing and only needs to have his error pointed out to him to induce an avoidance of it thereafter. This, of course, does not excuse the error which might result in harm to someone, but a distinction must be made between the degrees of an offense.

The pharmacist's position is a perplexing one, but not hopeless by any means. Of the various forms of adulteration, several are only likely by deliberate action. Those that are most troublesome are variation from standard strength, and inferior quality due to deterioration. It is not possible to shift the responsibility to the manufacturer or wholesaler in many cases. There is but one solution to the problem of how to deal with adulteration and that is found in eternal vigilance backed up by a large stock of information on the subject acquired by thorough training in our profession and constant reading of periodicals and newspapers.

Massachusetts College of Pharmacy, July, 1912.

\section{DISCUSSION.}

W. A. Puckner said he was pleased to hear one statement by the writer which agreed with a statement that he had recently made, viz.: that largely-used articles, whether medicines, foods or other commodities were likely to be pure. Where there is great competition a good 
product will be put on the market and purchased. This was one of the arguments which the Council on Pharmacy and Chemistry of the American Medical Association used in its propaganda for a restricted materia medica. Pharmacists should use only those drugs which are known to be good. If it was true that the preparations spoken of by the writer contained half a dozen different kinds of hypophosphites and acids, it showed that as to these very complex preparations the pharmacist sat upon a regular "dynamite mine," which was liable to explode at any time. He was using hundreds of drugs regarding the quality of which he was absolutely ignorant, and which he could not take the time to examine, and this was one reason why pharmacists should aid in the propaganda to restrict the medicaments used by the medical profession-to get away from complex mixtures, and stick to simple remedies.

G. H. P. Lichthardt heartily agrced with the statement that most of the adulteration in pharmacy was due to carelessness. He had occasion several years to examine certain specimens of citrate of magnesia, and had found in every case that their makers were using the old formula, having forgotten the extra acid added in the last revision of the formula. $\mathrm{He}$ believed this was happening every day. In his state where he had been engaged in this work for four or five years past, he had found pharmacists as a rule only too willing to cooperate with the authorities in the effort to keep down adulteration.

L. E. Sayre desired to call attention to the paragraph reading: "A substance is adulterated when it differs in any respect from the properties, strength, or quality, which have been defined by some competent authority." This, he said, was a very acceptable, condensed, definition of a standard for the administration of Food and Drugs Laws. This definition was especially valuable because frequently the administrators of the law were confronted with the question of standard where no definition adequate was found in the Pharmacopoia or National Formulary. Where a preparation was evidently adulterated and no recorded standard, such a standard would be valuable. It was not a question of wishing to prosecute vendors, but to stop the sale of adulterated preparations. A number of preparations had come to his laboratory where there was no definition or test in the Pharmacopœia or in the National Formulary by which to check their quality. If the above standard were applied it would serve a good purpose. Mr. Sayre said he thought there was a great opportunity here for applying the proposed tests. If an authority could be produced that would set a standard for a particular article, it would be greatly to the advantage of the administrators of the law and to pharmacy.

C. G. Clayton called attention to the duplication, or practical duplication, of names and formulas which had been suggested by the last two papers. Mr. Sass had displayed a specimen of elixir of iron, quinine and strychnine phosphates, and he had turned to a brother pharmacist at his side and asked if he had ever used that formula, eliciting the response that he used nothing except the elixir made from tincture of chloride of iron. He thought it inexcusable that, when one of these elixirs was prescribed, the other should be given; yet, when there was so nearly a duplication of names and formulas, with practically the same therapeutic effect, it was liable to create confusion in the minds of many dispensers. $\mathrm{He}$ thought this point worth considering by the compilers of the U. S. P. and N. F.

F. F. Gordon said he thought possibly it might be a good idea for this Section to go on record as defining the word "adulteration" in the words just read by Mr. Sayre from Mr. Bradley's paper, after which the matter might be referred to the Council for action, so that the Association itself might be placed on record as giving a clear and plain definition of the word "adulteration."

Caswell A. Mayo moved as a substitute that the definition of the word "adulteration" as set forth in Mr. Bradley's paper be recommended for consideration by the Committee on Resolutions of the House of Delegates.

The substitute was accepted by Mr. Gordon, and on motion was adopted. 